\title{
Desvelando os Sentidos da dor por meio de uma proposta Investigativa em Aulas de Ciências no Ensino Fundamental II
}

\section{Unveiling the Human pain meaning making through an Investigative Approach in Science Classes at Elementary School}

\author{
Mateus José dos Santos (mateus.j.santos@ufv.br) \\ Mestrando no Programa de Pós-graduação em Educação - Universidade Federal de Viçosa (UFV) \\ Rita Márcia Andrade Vaz de Mello (rmello@ufv.br) \\ Professora no Departamento de Educação - Universidade Federal de Viçosa (UFV) \\ Vinícius Catão (vcasouza@ufv.br) \\ Professor no Departamento de Química - Universidade Federal de Viçosa (UFV)
}

\begin{abstract}
Resumo: O presente trabalho descreve as repercussões educacionais na construção de um material didático voltado ao conteúdo de Ciências, a partir da leitura do livro "Aí que dor!". Ele termina com a seguinte questão que fomenta uma nova investigação: por que ao cortar os cabelos e as unhas não sentimos dor? Inspirados neste livro, 19 estudantes do $8^{\circ}$ Ano do Ensino Fundamental II produziram um material com explicações para esta pergunta. Ao final, aplicou-se um questionário semiestruturado, cujas respostas foram tratadas pela Análise de Conteúdo proposta por Bardin. Com base nos dados analisados, foi possível inferir que a atividade contribuiu para o entendimento da dor e de conceitos relativos ao sistema nervoso central e periférico, além de fomentar conteúdos atitudinais, tais como a cooperação e a autonomia. Destaca-se ainda que esta proposta foi desenvolvida a partir dos preceitos do Ensino de Ciências por Investigação (ENCI), estimulando os estudantes a se posicionarem ao longo de todo o processo.
\end{abstract}

Palavras-chave: Livros Paradidáticos. Ensino de Ciências por Investigação. Protagonismo Discente.

Abstract: This paper describes the educational repercussions in the construction of a didactic material focused on scientific content, from the reading of the Brazilian textbook "Aí que dor!". This textbook ends with a question that propose a relevant investigation: why do we not feel pain when cutting hairs and nails? Thereafter, 19 students from the Elementary School (13-14 years) produced new textbooks that propose explanations for this issue. Finally, they answered a semi-structured questionnaire, which was submitted to the Content Analysis proposed by Bardin. Based on the materials produced and the questionnaires answered, it was possible to infer that the educational activity contributed to the understanding of pain and concepts related to the central and peripheral nervous system, in addition to the attitudinal contents, such as cooperation and autonomy. It is also noteworthy that the proposal was developed based on the Investigative Science Education approach, encouraging students to position themselves throughout the entire process.

Keywords: Textbooks complementary. Investigative Science Education approach. Student Protagonism. 


\section{INTRODUÇÃ̃O}

Há uma tendência atual na Educação em Ciências que sugere uma abordagem de ensino mais direcionado à investigação como possibilidade de instigar os estudantes, em todos os níveis, a se interessarem mais pelas aulas de Ciências e a participarem de propostas formativas que contribuam efetivamente para uma formação mais humana, contextualizada e técnica (SANTOS; SCHNETZLER, 2010; RAIMONDI; RAZZOTO, 2020). A professora Anna Maria Pessoa de Carvalho, pioneira no desenvolvimento da proposta do Ensino de Ciências por Investigação (ENCI) no Brasil, define essa abordagem metodológica como sendo:

[...] o ensino dos conteúdos programáticos em que o professor cria condições em sua sala de aula para os alunos: pensarem, levando em conta a estrutura do conhecimento; falarem, evidenciando seus argumentos e conhecimentos construídos; lerem, entendendo criticamente o conteúdo lido; escreverem, mostrando autoria e clareza nas ideias expostas. Em consequência disso, quando avaliamos o ensino que propomos, não buscamos verificar somente se os alunos aprenderam os conteúdos programáticos, mas se eles sabem falar, argumentar, ler e escrever sobre esse conteúdo. (CARVALHO, 2018, p. 766).

O ENCI vai além da aprendizagem dos aspectos conceituais e procedimentais e pode favorecer o desenvolvimento da argumentação, do senso crítico, além da apropriação de novos conhecimentos a partir de situações-problemas que são abordadas nas aulas. Cabe ressaltar ainda que a proposta do ENCI deve incluir problematizações que sejam contextuais para os estudantes, de modo que eles possam se conectar com as situações de aprendizagem e assumir o protagonismo em todo o ciclo investigativo. Além disso, ao lançar mão de situações investigativas, tem-se a oportunidade de se desenvolver atitudes e valores, dentre eles a colaboração, o trabalho em equipe e a criatividade, que são demandadas durante o desenvolvimento de uma proposta com viés investigativo (POZO; CRESPO, 2009).

A definição do ENCI se mostra bastante abrangente, uma vez que há na literatura uma série de trabalhos que debatem esta abordagem metodológica por meio de diferentes situações de aprendizagem (LABURÚ; ZOMPÊRO, 2011). Entretanto, tais metodologias destacam a importância do protagonismo discente no desenvolvimento de atividades que proporcionam o pensar investigativo na compreensão dos conceitos científicos que perpassam a sala de aula. Este pensar investigativo é intrínseco ao ser 
humano e deve ser estimulado nas aulas. Nas palavras de Lorieri (2004), ancorado na perspectiva deweyneana de refletir sobre a prática, "investigamos porque necessitamos dessa função para nossa sobrevivência e para que possamos realizar escolhas acertadas em nossas vidas - pensar nossas escolhas nada mais é do que investigar” (p.74). Nesse sentido, Azevedo (2016) destaca que uma atividade pode ser considerada de investigação quando,

[...] a ação do aluno não deve se limitar apenas ao trabalho de manipulação ou observação, ela deve também conter características de um trabalho científico: o aluno deve refletir, discutir, explicar, relatar, o que dará ao seu trabalho uma característica de uma investigação científica. (AZEVEDO, 2016, p. 21).

Neste quesito, ao se desenvolver as propostas formativas com caráter investigativo nas aulas de Ciências, é importante que se tenha um problema de investigação bem delineado e que as discussões se encaminhem para um ciclo investigativo em que o estudante seja estimulado a pensar, a discutir e a criar a partir das interações com os seus pares. A interação assume um papel primordial no desenvolvimento das atividades investigativas na escola. Afinal, "a escola, enquanto espaço significativo de interação social oferece ao aluno a oportunidade de conviver coletivamente" (SEDANO; CARVALHO, 2017, p. 203). Além disso, concordamos com Sousa e Galiazzi (2017) quando destacaram que "a sala de aula é um lugar de compreender a Ciência para além dela mesma” (p. 281). Nesse sentido, a imersão neste ambiente plural demanda constantes interpretações sobre o que se aprende, de modo que o estudante tenha a oportunidade de construir suas ideias e de desenvolver um pensamento mais crítico e refletivo, atribuindo sentido ao conhecimento estudado.

Sasseron (2015) defende o ENCI como uma abordagem didática que propicia momentos de aprendizagens para além da transmissão de conceitos e a memorização de informações desconexas dos contextos dos estudantes. Nesta ótica, a autora defende que o ENCI pode ser implementado em diferentes componentes curriculares e no ensino de diversos conteúdos, constituindo-se uma prática formativa que se integra ao contexto educacional como um todo. Ainda nesse sentido, a autora aponta que o ENCI,

Denota a intenção do professor em possibilitar o papel ativo de seu aluno na construção de entendimento sobre os conhecimentos científicos. Por esse motivo, caracteriza-se por ser uma forma de trabalho que o professor utiliza na intenção de fazer com que a turma se engaje com as discussões e, ao mesmo tempo em que travam contato com fenômenos naturais, pela busca de resolução de um 
problema, exercitam práticas e raciocínios de comparação, análise e avaliação bastante utilizadas na prática científica. (SASSERON, 2015, p. 58).

É na escola que os estudantes poderão ter acesso e se apropriarem dos conhecimentos socialmente e historicamente construídos pelas tradições culturais: conhecimentos científicos que lhes propiciarão outras leituras do mundo, sobretudo mediados pela ação do professor que possibilita o protagonismo discente e favorece um espaço criativo de construção do conhecimento. Driver, Asoko, Leach, Mortimer e Scott (1999) destacaram que:

[...] aprender ciências não é uma questão de simplesmente ampliar o conhecimento dos jovens sobre os fenômenos - uma prática talvez denominada mais apropriadamente como estudo da natureza - nem de desenvolver ou organizar o raciocínio do senso comum dos jovens. Aprender ciências requer mais do que desafiar as ideias anteriores dos alunos, através de eventos discrepantes. Aprender ciências requer que crianças e adolescentes sejam introduzidos numa forma diferente de pensar sobre o mundo natural e de explicá-lo. (DRIVER et al., 1999, p. 36, destaque nosso).

As perspectivas para a Educação em Ciências debatidas atualmente estão voltadas para a possibilidade de construção permanente de conhecimentos condizentes com as transformações que vêm ocorrendo na sociedade. Fala-se, assim, na formação cidadã. Segundo Santos e Schnetzler (2010), a cidadania está diretamente ligada ao conceito de democracia. Esses autores ressaltaram ainda que educar para a cidadania demanda preparar o indivíduo para participar de uma sociedade democrática - em suas diversas instituições - não sendo a escola a única a contribuir para este processo. Sobre a contribuição da escola nesse processo formativo, Sacristán (1998) destaca que:

Mais do que transmitir a informação, a função educativa da escola contemporânea deve se orientar para provocar a organização racional da informação fragmentária recebida e a reconstrução das preconcepções acríticas, formadas pela pressão reprodutora do contexto social, por meio de mecanismos e meios de comunicação cada dia mais poderosos e de influência mais sutil. (SACRISTÁN, 1998, p. 26).

Com relação aos documentos oficiais, uma das competências específicas das Ciências da Natureza para o Ensino Fundamental contidas na Base Nacional Comum Curricular - BNCC - (BRASIL, 2018) aponta ser necessário: 
Compreender conceitos fundamentais e estruturas explicativas das Ciências da Natureza, bem como dominar processos, práticas e procedimentos da investigação científica, de modo a sentir segurança no debate de questões científicas, tecnológicas, socioambientais e do mundo do trabalho, continuar aprendendo e colaborar para a construção de uma sociedade justa, democrática e inclusiva. (BRASIL, 2018, p. 324).

Deste modo, a investigação também é mencionada na BNCC como possibilidade de contribuir para a discussão de questões que perpassam a sociedade como um todo e, consequentemente, que busca favorecer um ensino voltado a uma educação para a cidadania (SANTOS; SCHNETZLER, 2010). Nesse sentido, abre-se um leque de possibilidades em que o professor, a partir dos preceitos do ENCI, poderá articular nas aulas atividades que permitam aos estudantes uma imersão em práticas investigativas.

\subsection{SITUANDO O ENSINO DE CIÊNCIAS POR INVESTIGAÇÃO EM PROPOSTAS FORMATIVAS PARA O ENSINO FUNDAMENTAL II}

Para o componente curricular Ciências do Ensino Fundamental, há uma série de trabalhos que busca estimular os estudantes a participarem de atividades investigativas, incluindo-os em propostas formativas que os ajudem a pensar criticamente a partir das reflexões propiciadas pelo ENCI. Tais atividades estão voltadas tanto para os anos iniciais do Ensino Fundamental I (AZEVEDO, 2016; SANTANA; CAPECCHI; FRANZOLIN, 2018; BRITO; FIREMAN, 2018), quanto para os anos finais do Ensino Fundamental II (CARVALHO; HIGA, 2017; OLIVEIRA; NEVES, 2019; BRASIL; BRICCIA; SEDANO, 2019).

Envolver os estudantes em ciclos investigativos desde os anos iniciais pode motivá-los a se interessarem pelas Ciências e a aprenderem a problematizar os conceitos discutidos em sala de aula. Além disso, tais atividades tem o potencial para favorecer a Alfabetização Científica (AC). Nesta perspectiva, Chassot (2006) reforça que quando os sujeitos são capazes de relacionar os conhecimentos científicos para resolver situações da vida cotidiana, pode-se inferir que os mesmos se alfabetizam cientificamente.

Munford e Lima (2008) já apontam que não há novidade em propor um ensino com perguntas e respostas sem estimular o estudante a pensar. Deste modo, o ENCI atua como uma relevante metodologia aliada ao processo de ensino e aprendizagem. Atividades ancoradas no ENCI podem permitir que o estudante saía da zona de conforto e assuma uma postura ativa frente a situações articuladas pelo professor em sala de aula. 
Uma das possibilidades de se desenvolver propostas fundamentadas no ENCI é por meio das Sequências de Ensino Investigativas (SEI), que podem ser denominadas como "o encadeamento de atividades e aulas em que um tema é colocado em investigação e as relações entre esse tema, conceitos, práticas e relações com outras esferas sociais e de conhecimento possam ser trabalhadas" (SASSERON, 2015, p. 59). No entanto, a proposta do ENCI pode estar atrelada a outras estratégias didáticas, tais como o júri simulado, a experimentação, seminários, construção de materiais didáticos, dentre outras possibilidades a serem realizadas em espaços formais e não formais de educação. Contudo, é importante que tais atividades estimulem o raciocínio dos estudantes, incentivando-os a proporem hipóteses que resultem na problematização, no desenvolvimento da argumentação e na tomada de decisões (CARVALHO, 2013).

Cabe também uma reflexão sobre a importância de se desenvolver práticas formativas relacionadas ao ENCI já no Ensino Fundamental. Isso pode estimular os estudantes a se posicionarem com maior consciência e criticidade frente o conhecimento científico, articulando os conceitos abordados nas diferentes atividades discutidas. Uma proposta de ENCI bem planejada nos anos iniciais e finais do Ensino Fundamental pode contribuir para o desenvolvimento do estudante nos segmentos posteriores.

Partindo dessas premissas, o presente trabalho descreve uma experiência investigativa implementada com 19 estudantes do $8^{\circ}$ Ano Ensino Fundamental II (EFII). Os estudantes discutiram o livro "Aí que dor" (REIS; CONTIJO; HOFFERT, 2018), que explica de maneira lúdica o porquê sentimos dor. O livro termina com uma pergunta investigativa, convidando os estudantes a responderem o porquê ao cortar os cabelos e as unhas não sentimos dor? (REIS; CONTIJO; HOFFERT, p. 24). Permeado por esse ambiente de curiosidade, o professor e os estudantes tiveram a ideia de construir um livro paradidático para responder a essa questão proposta no livro. A escolha por fazer o material paradidático deu-se pelo fato de quê o livro, além de se comportar "como um artefato preferencialmente estimulante" (COSTA, 2010, p. 42), possui características flexíveis, possibilitando o "entretenimento até o estímulo à leitura, seja no ambiente escolar, sejam em outros ambientes" (COSTA, 2010, p. 42). Além disso, os livros paradidáticos permitem que os sujeitos ousem em sua criação, dando liberdade para a exposição das ideias que emergem no momento de sua confecção. Costa (2010) aponta que a utilização dos livros paradidáticos se fundamenta na 
[...] necessidade de um reforço de mensagens de caráter mais social. As histórias contidas neles têm, em geral, mensagens implícitas sobre: moral, comportamento, civilidade, preocupação ambiental, companheirismo, entre outras. (COSTA, 2010, p. 43).

Pautado no ENCI, ao inserir em sala de aula a utilização de problemas e questões investigativas que estimulam a curiosidade e estabelecem um desafio de aprendizagem aos estudantes (PEDASTE et al., 2015), objetivou-se a apresentação e discussão das narrativas apresentadas nos livros paradidáticos construídos nesse processo que envolveu os discentes, visando entender o potencial da atividade implementada para o desenvolvimento da capacidade crítico-reflexiva dos participantes, pautados no ciclo investigativo proposto nas aulas de Ciências, conforme discutido por Lorenzon (2018).

\section{METODOLOGIA}

Essa pesquisa, com abordagem qualitativa, descreve os livros paradidáticos elaborados por 19 estudantes do $8^{\circ}$ Ano do EFII de um colégio particular situado na cidade de Ervália (MG). A escolha pela pesquisa qualitativa deve-se ao fato de que ela reúne multiparadigmas que possibilitam contextos de produção plurais em busca da resposta para uma dada questão de pesquisa (CHIZZOTI, 2003). Pretende-se com esta pesquisa avaliar os livros paradidáticos elaborados pelos estudantes e o impacto desta atividade no processo de ensino e aprendizagem dos conceitos científicos abarcados pela atividade formativa.

A pesquisa qualitativa adotada aqui preocupa-se com os sentidos elaborados pelos sujeitos durante a caminhada metodológica. A perspectiva desta pesquisa permite ir além dos parâmetros quantitativos e está centrada na interpretação dos sentidos produzidos por um grupo pesquisado (SILVEIRA; CORDÓVA, 2009). Deste modo, buscamos ao analisar o material elaborado pelos discentes, interpretá-lo à luz da literatura, com vistas a compreender a repercussão desta atividade na formação humana e sociocientífica dos sujeitos envolvidos.

Para o desenvolvimento desta proposta, os estudantes foram divididos em seis grupos visando à elaboração de livros paradidáticos que explicassem o porquê ao cortarmos as unhas e os cabelos não sentimos dor. Eles poderiam construir a narrativa que quisessem, desde que ela fosse discutida em grupos nas aulas de Ciências e correlacionada com os aspectos conceituais trabalhados sobre o Sistema Nervoso (SN). Para a elaboração desta proposta, todos participaram de uma sequência de aulas expositivas sobre o SN, que abordou os assuntos apresentados no Quadro 1. 
Quadro 1: Sequência de assuntos das aulas expositivas sobre o Sistema Nervoso.

\begin{tabular}{|c|l|}
\hline Aulas & \multicolumn{1}{c|}{ Assuntos abordados } \\
\hline 1 & Características morfológicas e anatômicas do SN. \\
\hline 2 & As sinapses e os neurotransmissores \\
\hline 3 & Sistema Nervoso Central (SNC) \\
\hline 4 & Sistema Nervoso Periférico (SNP) \\
\hline 5 & Dor e sua relação com o Sistema Nervoso (SN). \\
\hline
\end{tabular}

Fonte: Os autores.

A sequência de aulas terminou com a discussão sobre a dor e o SN. Em seguida, o professor propôs a leitura em grupo do livro "Aí que Dor!" (REIS; CONTIJO, HOFFERT, 2018), sendo esta uma atividade complementar à discussão iniciada nas aulas. O livro suscitou diálogos efetivos sobre o conteúdo referente ao $\mathrm{SN}$, o que gerou a ideia de desenvolvimento de novas histórias sobre a temática proposta pelo livro. Em grupos, os estudantes interagiram e construíram novas narrativas. A Figura 1 apresenta a capa de dois livros construídos pelos estudantes ao longo desta atividade.

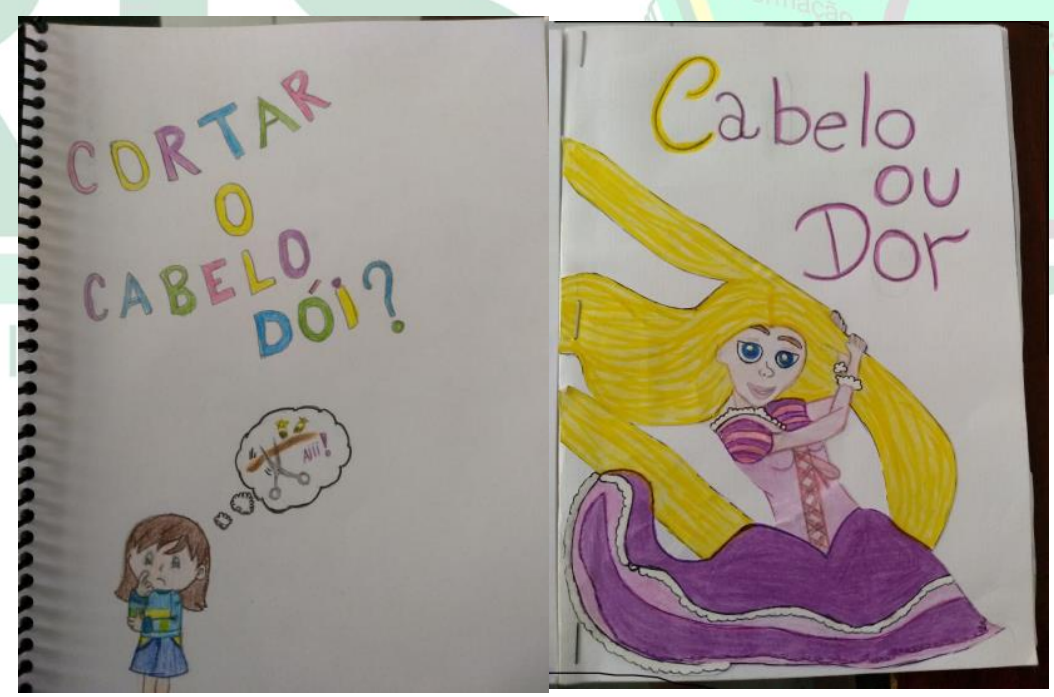

Figura 1: Capa dos livros paradidáticos elaborados pelos grupos 1 e 2.

Após a construção e elaboração dos livros paradidáticos, os estudantes apresentaram as narrativas construídas nas aulas de Ciências para a turma. Todos os grupos leram suas histórias e contaram como foi a interação entre eles para a concretização desta atividade. Posteriormente, cada estudante respondeu voluntariamente a um questionário contendo quatro questões sobre o desenvolvimento desta atividade. Será analisada aqui a seguinte questão: $O$ que você aprendeu de importante com esse trabalho? 
Para analisar as respostas dos estudantes participantes, utilizaremos a Análise de Conteúdo de Bardin (AC) (BARDIN, 2013). A AC possibilita desconstruir as respostas em unidades de análise (UA), consistindo em frases simples que, por si só, exprimem um significado completo. Em seguida, as UA serão agrupadas em categorias que emergem dos significados destas UA, processo conhecido como categorização. Por fim, as categorias foram interpretadas à luz da literatura, possibilitando uma análise crítica e minuciosa da repercussão das atividades realizadas na formação dos estudantes.

\section{RESULTADOS E DISCUSSÃO}

No desenvolvimento desta atividade, foi notório o engajamento dos estudantes para a elaboração dos livros paradidáticos, sendo sugerido a eles que escrevessem histórias voltadas ao público infanto-juvenil, para que eles também tivessem contato com as temáticas científicas em questão. Desse modo, os estudantes foram divididos em seis grupos (G1 a G6), sendo cinco com três componentes e um com quatro. Cada grupo elaborou um novo material com desenhos e enredos originais, dialogando com o livro central proposto para a leitura e debate nas aulas de Ciências. Ainda, as histórias perpassavam pela questão da dor, mas os estudantes tiveram liberdade para construir as narrativas que lhes interessassem, desenvolvendo um enredo que fosse interessante aos futuros leitores dos livros, o que demandou uma reflexão conjunta entre todos os integrantes do grupo. É importante que os livros paradidáticos desenvolvam o apreço pela leitura nos mais variados componentes curriculares. Desta forma, deve apresentar uma narrativa que estimule e crie o interesse do leitor, conforme assevera Laguna (2011) ao referir-se que a leitura paradidática

[...] apresenta-se com o objetivo de despertar nas pessoas o prazer de ler, reconhecendo-se o ato de ler como capaz de instruir, divertir, fazer sonhar com projetos pessoais, políticos, de justiça, de amor e paz. (LAGUNA, 2011, p. 43).

Os seis livros originados desta atividade demonstraram a importância do estímulo ao protagonismo discente nas aulas de Ciências. A liberdade de criação proporcionou aos grupos debaterem abertamente sobre suas ideias e chegarem a um consenso, estimulando não só a pesquisa de temáticas científicas, mas o desenvolvimento de atitudes e valores nas aulas. Tal situação de aprendizagem vai ao encontro do que salienta Souza e Carvalho (2005), reforçando a importância de se desenvolver os aspectos socioemocionais na escola, sendo esse um ambiente coletivo que: 
[...] oferece à criança a oportunidade de estabelecer relações, conviver num espaço social com outras crianças e com adultos. Estas relações são pautadas em atitudes que, por sua vez, baseiam-se em valores; valores estes que não são passados ou internalizados, e sim construídos na interação social, enquanto processo de construção da autonomia moral. (SOUZA; CARVALHO, 2005, p. 2).

A seguir, será apresentado o enredo de cada um dos livros paradidáticos construídos pelos estudantes e alguns fragmentos dos materiais elaborados.

\subsection{DESVENDANDO OS MISTÉRIOS DA DOR: O QUE NOS CONTARAM OS ESTUDANTES SOBRE ESTA QUESTÃO?}

Os livros construídos nas aulas de Ciências foram enumerados de L1 a L6, cada um com uma história diferente que retratou a visão que o grupo possuía sobre o conceito da dor e sua relação com o SN, conforme discutido nas aulas de Ciências e também em pesquisas realizadas em outros momentos extraclasses. O Grupo 1 decidiu retratar a história de uma menina que após ouvir sobre o $\mathrm{SN}$ e a dor tinha medo de cortar o cabelo, pois achava que iria sofrer muito. A criança precisou conversar com a professora para que a sua dúvida sobre o tema fosse sanada. Já o Grupo 2 narrou a história de um menino que antes tinha medo de cortar o cabelo, mas cresceu e aprendeu que o corte não faz sentir dor e descreve o cabelo como algo inato da personalidade humana, propiciando reflexões além dos aspectos conceituais. Este grupo explorou outras funções do cabelo, atribuindo significado estético e identidade, o que trouxe novos elementos para serem debatidos nas aulas de Ciências. A Figura 2 apresenta excertos dos livros produzidos pelos Grupos 1 e 2 .

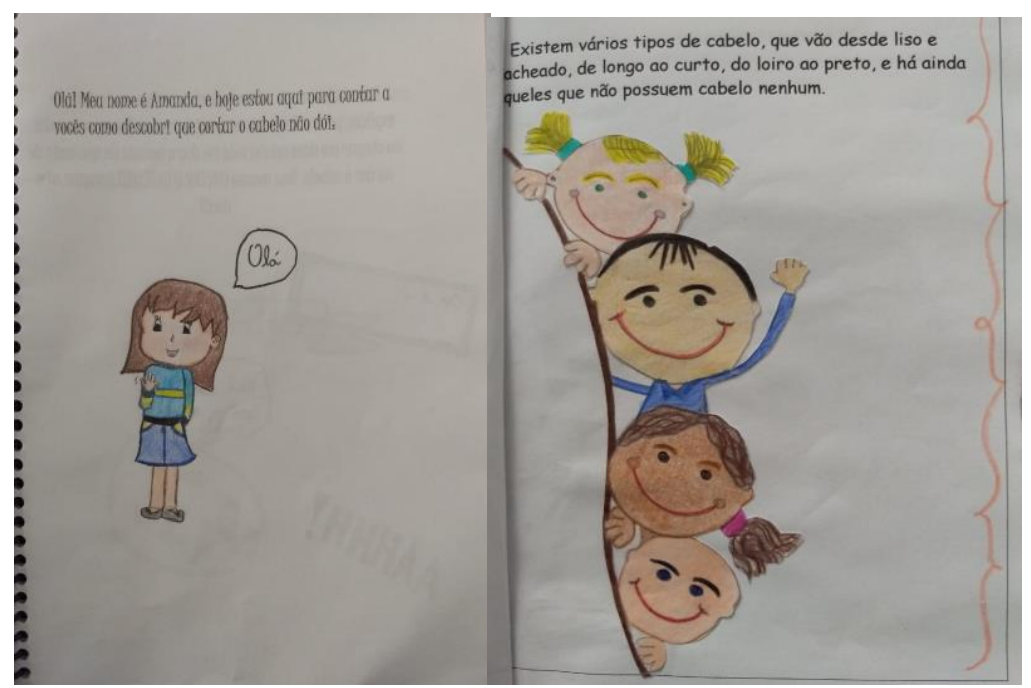


Figura 2: Trechos dos livros produzidos pelos grupos 1 e 2.

Os fragmentos dos livros trazidos na Figura 2 demonstram a criatividade dos estudantes na elaboração da atividade. A originalidade dos desenhos e das narrativas mostra a necessidade de estimularmos o protagonismo discente nas aulas, fugindo da mera passividade ainda persistente na Educação em Ciências.

Os Livros 3 e 4 também conservaram as características criativas e originais descritas anteriormente. O grupo 3, por exemplo, preocupou-se em contar uma história científica, focada na questão central orientada pelo professor, por meio de uma linguagem mais infantil, utilizando termos discutidos nas aulas de Ciências. Colocaram as células e o cabelo como personagens, visando assim estimular a curiosidade do público leitor. Após a apresentação deste livro em sala, os estudantes salientaram que dar vida aos seres inanimados pode propiciar um estímulo maior para a leitura do livro, mas que é preciso ter atenção, uma vez que estes personagens possuem vida apenas na ficção, com o intuito de propiciar a persuasão durante a leitura. Essa se mostrou uma visão bastante crítica e madura para abordar aspectos teórico-conceituais das Ciências em geral.

Já no Livro 4, descreveu-se um episódio entre uma mãe e sua filha no salão de beleza, onde a mãe explica o porquê não sente dor ao cortar os cabelos e as unhas. A Figura 3 apresenta fragmentos dos livros mencionados.
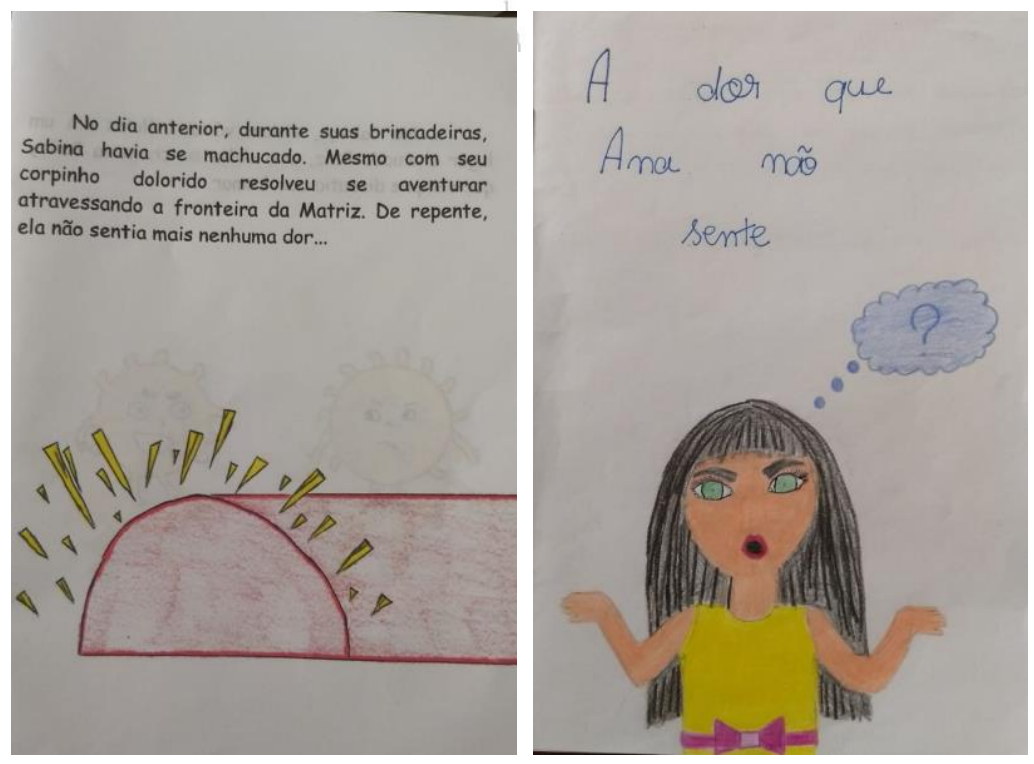

Figura 3: Fragmentos dos livros produzidos pelos Grupos 3 e 4. 
O Grupo 5 optou por descrever uma narrativa entre uma criança e o cabeleireiro sobre a questão da dor ao cortar o cabelo. O cabeleireiro explica com detalhes o fato de não sentir dor ao cortar o cabelo, buscando amenizar o medo aparente. Por fim, o Grupo 6 descreveu a história de um menino que estava receoso de levar seu animal (um cão), recém encontrado na rua, para tosar o pelo e cortar as unhas. No petshop, a médica veterinária explicou que tal procedimento não faria com que o cão sentisse dor. Após este episódio, o dono do animal encontrou o cão perdido, deixando o menino triste. Isso fez com que os integrantes do Grupo 6 também abordassem a dor psicológica, temática discutida nas aulas sobre o SN. Desta forma, o Grupo 6 intitulou o livro elaborado como “A dor de Luiz", abordando diferentes tipos de dor e fazendo correlações com as discussões trazidas nas aulas. A Figura 4 ilustra fragmentos dos dois últimos livros produzidos pelos Grupos 5 e 6.

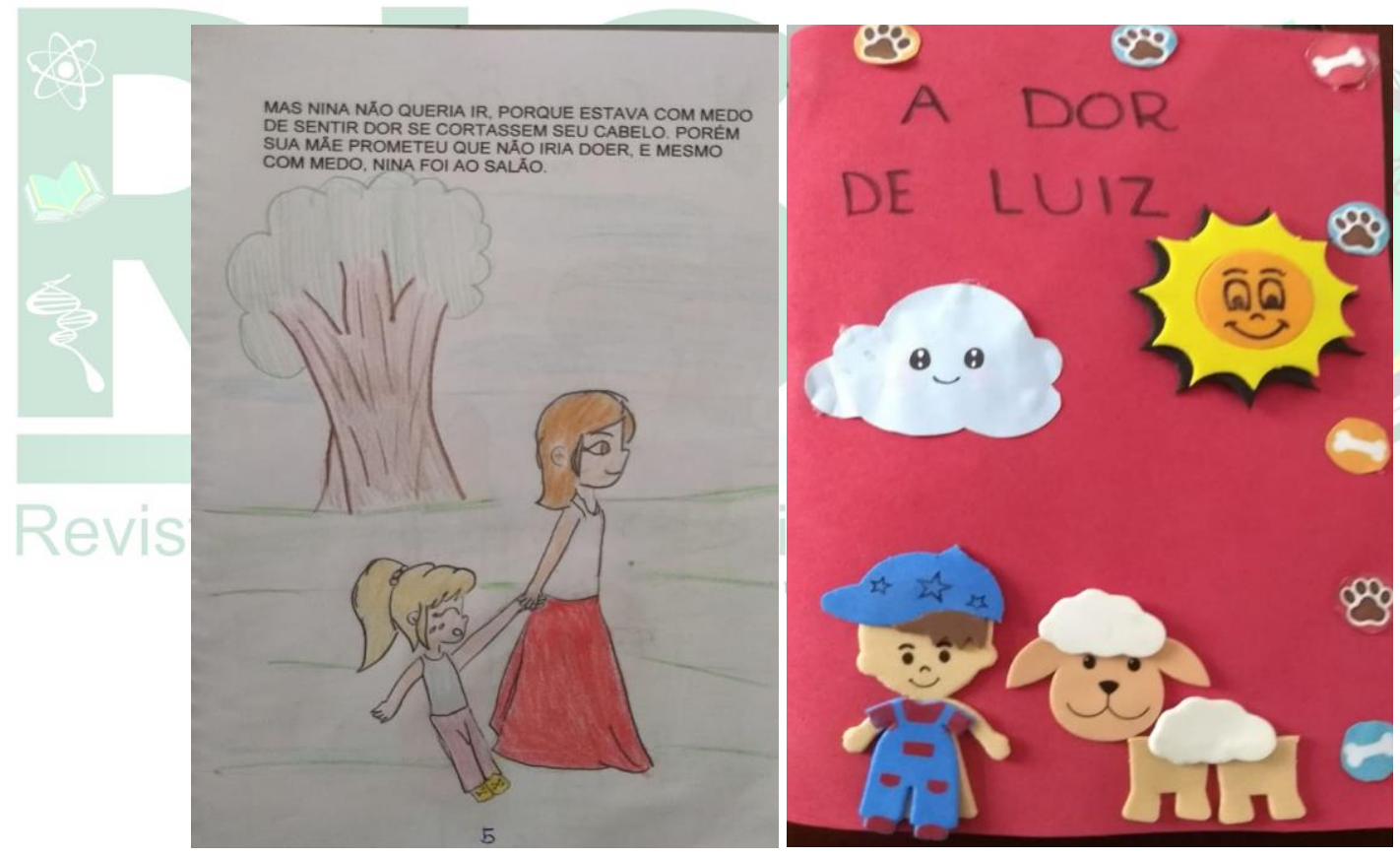

Figura 4: Trechos dos livros produzidos pelos Grupos 5 e 6.

Durante as aulas, verificou-se que os estudantes estavam imersos em um ciclo de ENCI, uma vez que todos buscaram responder a problemática inicial proposta pelo livro paradidático “Ai que dor!”. A partir de então, os grupos centraram suas pesquisas na busca pelo desenvolvimento da proposta e preocuparam-se em escrever os novos livros com uma linguagem mais simples e acessível, para que outras crianças e jovens também pudessem compreender a proposta do material. 
Após a elaboração dos livros paradidáticos, os grupos apresentaram o material, fazendo as leituras das narrativas nas aulas de Ciências. Verificou-se ainda que os estudantes demonstraram grande interesse e envolvimento em todo o processo. De acordo com Zuliane (2006), é importante que se proponha atividades contextuais, que estimule os estudantes à novas descobertas. Segunda a autora,

É necessário, portanto, que o indivíduo tenha interesse e necessidade de aprender para que se disponha a fazê-lo. Para que isto seja possível, as atividades propostas aos sujeitos devem ser escolhidas, partindo do pressuposto de serem contidas no universo de seus interesses [...]. (ZULIANI, 2006, p.40).

Cabe ressaltar ainda que as atividades foram discutidas com os estudantes durante todo o processo, propiciando diálogos profícuos na sua elaboração e possibilitando ao professor assumir o papel de mediador no processo de ensino e aprendizagem. Com base em Carvalho (2011), os preceitos do ENCI foram respeitados, uma vez que houve uma problematização bem delimitada e os estudantes resolveram a situação-problema a partir de narrativas discutidas em grupos, apresentando as ideias das equipes na culminância dos trabalhos.

\subsection{A CONSTRUÇÃO DOS LIVROS PARADIDÁTICOS E A APRENDIZAGEM DE CONCEITOS CIENTÍFICOS}

Após a elaboração dos livros, os estudantes responderam a um questionário semiestruturado que versava sobre alguns dos conceitos abordados durante $\mathrm{o}$ desenvolvimento desta atividade. A questão a ser analisada aqui será: $O$ que você aprendeu de importante com esse trabalho? A análise das respostas permitiu a elaboração de categorias primárias e finais. O Quadro 2 a seguir sumariza as categorias primárias que emergiram na análise das respostas dos estudantes.

Quadro 2: Conhecimentos favorecidos pela elaboração dos livros paradidáticos.

\begin{tabular}{|c|l|}
\hline \multicolumn{1}{|c|}{ Categorias primárias (n=7) } & \multicolumn{1}{|c|}{ Manifestações (n=28) } \\
\hline Conhecimento sobre a dor física & $\begin{array}{l}\text { E2, E4, E5, E6, E9, E10, E12, } \\
\text { E13, E14, E16. }\end{array}$ \\
\hline Explicar uma temática científica & E1, E2, E3, E7, E11, E15. \\
\hline Escrita de um livro & E9, E12, E13, E16. \\
\hline Conhecimento sobre dor emocional/psicológica & E2, E16, E17. \\
\hline Conhecimento sobre diferentes tipos de dor & E7, E14. \\
\hline Descobertas sobre o SN (central e periférico) & E8, E10. \\
\hline Aprofundar sobre os conhecimentos do SN & E11. \\
\hline
\end{tabular}


Fonte: Os autores.

Dos 19 estudantes participantes da construção dos livros paradidáticos, 17 deles aceitaram responder voluntariamente o questionário ao final das atividades. A identidade deles foi preservada, atribuindo o código EX, sendo X um número de ordem atribuído aleatoriamente de 1 a 17 . A proposta deste trabalho buscou compreender um pouco mais sobre o universo da dor e do SN, por meio da construção de livros paradidáticos, ancorado na proposta do ENCI. Após a sequência de aulas expositivas e a construção do livro, os estudantes expuseram o que aprenderam, dando origem às categorias primárias dispostas no Quadro 2. As categorias primárias nos possibilitaram enquadrar os conhecimentos dos estudantes em outras duas grandes categorias finais: (i) conhecimento de conceitos sobre o SN/Dor; e (ii) conhecimento sobre a linguagem científica. O Quadro 3 apresenta esta nova (re)organização das categorias.

Quadro 3: Reorganização das categorias e subcategorias da questão analisada.

\begin{tabular}{|c|c|}
\hline Categorias Finais & Categorias Primárias \\
\hline $\begin{array}{l}\text { Conhecimento de } \\
\text { conceitos sobre o } \\
\text { SN/Dor } \\
\text { ista Insional }\end{array}$ & $\begin{array}{l}\text { - Conhecimento sobre dor Física; } \\
\text { - Conhecimento sobre dor emocional/psicológica; } \\
\text { - Conhecimento sobre diferentes tipos de dor; } \\
\text { - Descobertas sobre o SN; } \\
\text { - Aprofundar sobre os conhecimentos do SN. }\end{array}$ \\
\hline $\begin{array}{l}\text { Conhecimento sobre } \\
\text { a linguagem científica }\end{array}$ & $\begin{array}{l}\text { - Explicar uma temática científica; } \\
\text { - Escrita de um livro. }\end{array}$ \\
\hline
\end{tabular}

Fonte: Os autores.

Com base nesta nova organização, verificou-se que os estudantes explicitaram aprendizagens conceituais que perpassam pelo universo das Ciências e está em consonância com o conteúdo programático planejado para o componente curricular supracitado. As manifestações dos estudantes abarcaram os conceitos relacionados ao SN, tal como foi exposto no Quadro 1. Ainda, abordagens sobre a dor e os impactos no SN apareceram nas discussões em grupo. Nesta discussão sobre a dor, foram debatidas questões relacionadas à dor física e psicológica e os possíveis efeitos sentidos tanto no corpo, quanto no âmbito emocional. As manifestações a seguir exemplificam algumas das situações enquadradas nesta categoria final. 
Que é muito interessante essa questão da dor, eu nunca havia parado para pensar nesse assunto, e além de tudo, aprendi que nosso corpo é muito amplo. Quantos aspectos o sistema nervoso pode abordar. (E8)

Aprendi a diferença de várias dores, porque até então eu nunca havia parado para pensar. Aprendi também que nem todas as coisas mortas são inúteis. (E14)

Outra categoria que emergiu está associada ao conhecimento sobre a escrita e a explicação do livro paradidático. Segundo alguns dos estudantes, esta foi a primeira vez que os mesmos elaboram um livro voltado a uma temática científica. A seguir, são apresentadas duas manifestações dos estudantes que ilustram esta categoria.

[Ajudou] A explicar de maneira mais clara e compreensível uma temática científica. (E1)

Com esse trabalho eu aprendi que existem outras formas de transmitir conhecimentos científicos, além de uma explicação em forma de "aula". Nós podemos usar a nosso favor e atingir um público-alvo maior: as crianças. (E15)

As categorias primárias demonstram a importância de estimular o contato com temas científicos na Educação Básica a partir de atividades investigativas que coloquem os estudantes para pensarem sobre os conceitos que aprendem, estimulando à Alfabetização Científica. Nesta perspectiva, Souza e Sasseron (2012) apontam que,

O alfabetizado cientificamente, assim como um cientista, não precisa saber tudo sobre as Ciências, mas deve ter conhecimentos suficientes de vários de seus campos e saber sobre como esses estudos se transformam em adventos para a sociedade, no sentido de compreender de que modo tais conhecimentos podem afetar sua vida e a do planeta. $\mathrm{O}$ foco deixa de estar somente no ensino de conceitos e métodos das Ciências, mas também sobre a natureza das Ciências e suas implicações mútuas com a sociedade e o ambiente. (SOUZA; SASSERON, 2012, p. 596).

É importante destacar também que o protagonismo discente foi favorecido nas aulas, sobretudo pela possibilidade de os estudantes exporem suas ideias e discuti-las em grupos, a partir da mediação do professor.

\section{CONSIDERAÇÕES FINAIS}

Com o desenvolvimento deste trabalho, verificou-se a relevância de desenvolver atividades investigativas na Educação Básica que propiciem uma Alfabetização Científica por meio de práticas didático-pedagógicas que permita aos discentes 
exteriorizarem suas ideias e favoreçam situações de aprendizagem criativas. Cabe ressaltar que muitas atividades centradas no ENCI ainda perpassam por SEI com propostas de ensino fechadas e que não exploram outras estratégias, tais como a elaboração de livros paradidáticos. Esta atividade além de seguir os preceitos do ENCI, favoreceu também aos estudantes a possibilidade de criarem narrativas para compreender uma determinada temática científica.

A interação entre os estudantes nos grupos e entre os estudantes e o professor foi primordial no desenvolvimento da proposta formativa e proporcionou $\mathrm{o}$ desenvolvimento não só dos conteúdos conceituais, mas também atitudes e valores nas aulas de Ciências. A curiosidade, a cooperação, a tomada de decisão, a autonomia foram alguns conteúdos atitudinais fomentados durante a elaboração dos livros paradidáticos e a exposição dos mesmos nas aulas. A articulação entre os aspectos conceituais e os atitudinais pode possibilitar ao estudante se apropriar dos conhecimentos abordados nas aulas e estabelecer interconexões com os seus saberes prévios, contribuindo desta forma para a construção do conhecimento em uma perspectiva mais humana.

A confecção do livro paradidático usando uma linguagem infanto-juvenil levou os estudantes para um universo de criação, do despertar para o novo, fazendo com que eles percebessem que as aulas de Ciências podem propiciar uma gama de atividades diversificadas que extrapolam os muros da escola. As aulas não ficaram apenas centradas na explicação dos conceitos ligados ao SN ou que explicasse a relação deste sistema com a dor. Os debates foram além destes temas e incentivaram os estudantes a exporem suas experiências com a dor, seja ela física ou psicológica, além de estabelecer diálogos com os conceitos científicos e suas vivências pessoais. Desse modo, a AC foi possível e viável mediante as pesquisas realizadas pelos estudantes, as propostas explicativas trazidas e o vínculo realizado entre o que abordou em sala de aula e a vida em sociedade. Acreditamos que isso possibilitou uma educação com viés crítico, reflexivo e voltada à formação cidadã nas aulas de Ciências.

\section{REFERÊNCIAS}

AZEVEDO, Lidiany Bezerra Silva de. Ensino de Ciências por Investigação nos anos iniciais do Ensino Fundamental: Estudos dos conceitos básicos de eletricidade para a promoção da Alfabetização Científica. 142 f. Dissertação (Mestrado em Ensino de 
Ciências e Matemática) - Programa de Pós-Graduação em Ensino de Ciências e Matemática, Universidade Federal de Alagoas, 2016.

AZEVEDO, Maria Cristina P. Stella de. Ensino por investigação: Problematizando as atividades em sala de aula. In: CARVALHO, Anna Maria Pessoa de (ORG). Ensino de Ciências: Unindo a pesquisa e a prática. 1. Ed, São Paulo: Cengage Learning, 2004, p. $19-33$.

BARDIN, Laurence. Análise de conteúdo. Lisboa: Edições 70, 2013. 281 p.

BRASIL, Therezinha Vasconcelos Santos; BRICCIA, Viviane; SEDANO, Luciana. As contribuições de uma atividade experimental investigativa par ao processo de Ensino e Aprendizagem de fungos. In: XII ENPEC, 2019, Natal. Atas...Natal: ENPEC, 2019. p. $1-9$.

BRASIL. Base Nacional Comum Curricular. Brasília: MEC, 2018. Disponível em: http://basenacionalcomum.mec.gov.br/images/BNCC_EI_EF_110518_versaofinal_site. pdf. Acesso em: 12 de Janeiro de 2020.

BRITO, Liliane de Oliveira de; FIREMAN, Elton Casado. Ensino de Ciências por investigação: Uma proposta didática "para além" de conteúdos conceituais. Experiências em Ensino de Ciências, v. 13, n. 5, p. 462-479, 2018.

CARVALHO, Anna Maria Pessoa de. Ensino e aprendizagem de ciências: referenciais teóricos e dados empíricos das sequências de ensino investigativas (SEI). In: O uno e o diverso na educação. Uberlândia: EDUFU, 2011.

CARVAlHO, Anna Maria Pessoa de. Fundamentos Teóricos e Metodológicos do Ensino por Investigação. Revista Brasileira de Pesquisa em Educação em Ciências, v. 18, n. 3, p. 765-794, 2018.

CARVAlHO, Anna Maria Pessoa de. O ensino de ciências e a proposição de sequências de ensino investigativas. In: CARVALHO, A. M. P. (Org.). Ensino de ciências por investigação: condições para implementação em sala de aula. São Paulo: Cengage Learning, 2013. p. 1-20.

CHASSOT, Attico. Alfabetização científica: questões e desafios para a educação. 4a. ed. Ijuí: Unijuí, 2006. 
CHIZZOTTI, Antônio. A pesquisa qualitativa em Ciências Humanas e Sociais: evolução e desafios. Revista Portuguesa de Educação, v. 16, n. 2, p. 221-236, 2003.

COSTA, Elizabelle Pereira. A cultura visual paralela: o design do Livro Infantil paradidático. 44f. Dissertação (Mestrado de Design) - Centro de Artes e Comunicação, Universidade Federal de Pernambuco, Recife, 2010.

DRIVER, Rosalind; ASOKO, Hilary; LEACH, John; MORTIMER, Eduardo Fleury; SCOTT, Philip. Constructing scientific knowledge in classroom. Educational Researcher, v.23, n.7, p. 5-12, 1994. In: Tradução de MORTIMER, Eduardo. Construindo conhecimento científico em sala de aula. Química Nova na Escola, n.9, p.31-40, 1999.

HIGA, Ivanilda; CARVALHO, Adriana de Fátima Nibichiniack. O ensino por investigação em Ciências na escola pública: compreendendo sua relevância a partir do relato dos alunos. In: XIII EDUCERE - Congresso Nacional de Educação, 2017, Curitiba. Anais... Curitiba: PUCPRess - Editora Universitária Champagnat, 2017. p. 7161-7170.

LAGUNA, Alzira Guiomar Jerez. A contribuição do livro paradidático na formação do aluno-leitor. Augusto Guzzo Revista Acadêmica, n. 2, p. 43-52, 2001.

LORENZON, Mateus. Os portifólios como instrumento avaliativo em uma proposta de Ensino por Investigação. Revista Insignare Scientia, v.1, n.3, set./dez., p.1-18, 2018.

LORIERI, Marcos Antônio. Aprender a investigar educação básica. EccoS Revista Científica, v. 6, n. 2, p. 67-85, 2004.

MUNFORD, Danusa. ; LIMA, Maria Emília Caixeta de Castro. Ensinar ciências por investigação: em quê estamos de acordo? Revista Ensaio, v. 9, n.1, p. 89-111, 2008.

OLIVEIRA, Sérgio Geraldo Torquado de; NEVES, Maria Luíza da Costa. A motivação de estudantes do Ensino Fundamental para aprender ciências em aulas investigativas na perspectiva da teoria da autodeterminação. In: XII ENPEC, 2019, Natal. Atas... Natal: ENPEC, 2019. p. 1-7.

PEDASTE, Margus; MÄEOTS, Mario; SIIMAN, Leo A.; JONG, Ton de; RIESEN, Siswa A. N. van; KAMP, Ellen T., MANOLI, Constantinos, C. ; ZACHARIAS C. 
Zacharia; TSOURLIDAKI, Eleftheria. Phases of inquiry-based learning: Definitions and the inquiry cycle. Educational Research Review, v. 14, p. 47-61, 2015.

POZO, Juan Ignacio; CRESPO, Miguel Ángel Gómez. A aprendizagem e o ensino de ciências: do conhecimento cotidiano ao conhecimento científico. 5. ed. Porto Alegre: Artmed, 2009.

RAIMONDI, Angela Cristina; RAZZOTO, Eliane Siqueira. Aprendizagem baseada em problemas no Ensino de Química Analítica. Revista Insignare Scientia, v.3, n.2, p.3648, 2020.

REIS, Débora; CONTIJO, Helena; HOFFERT, Luciana. Ai que Dor! Belo Horizonte: Estraladabão, 2018.

SACRISTÁN, José Gimeno. Compreender e transformar o Ensino. Trad. Ernani F. da Fonseca Rosa, $4^{\mathrm{a}}$ ed. Artmed, 1998.

SANTANA, Ronaldo Santos; CAPECCHI, Maria Cândida Varone de Morais; FRANZOLIN, Fernanda. O ensino de ciências por investigação nos anos iniciais: possibilidades na implementação de atividades investigativas. Revista Electrónica de Enseñanza de las Ciencias, v. 17, n. 3, p. 686-710, 2018.

SANTOS, Wildson Luis Pereira; SCHNETZLER, Roseli Pacheco. Educação em química: compromisso com a cidadania. - 4ª ed. rev. Atual. Ijuí: Ed. Unijuí, 2010.

SASSERON, Lúcia Helena. Alfabetização Científica, Ensino por Investigação e argumentação: Relações entre Ciências da Natureza e Escola. Ensaio, v. 17, n. especial, p. 49-57, 2015.

SEDANO, Luciana; CARVALHO, Anna Maria Pessoa de. Ensino de Ciências por Investigação: Oportunidades de Interação Social e sua importância para a Construção da Autonomia Moral. Alexandria, v. 10, n. 1, p. 199-220, 2017.

SILVEIRA, Denise Tolfo; CÓRDOVA, Fernanda Peixoto. A pesquisa científica. In: GERHARDT, Tatiana Engel; SILVEIRA, Denise Tolfo (Orgs.). Métodos de pesquisa. Porto Alegre: Editora da UFRGS, 2009.

SOUSA, Robson Simplicio de; GALIAZZI, Maria do Carmo. Trações da Hermenêutica Filosófica na Educação em Ciências: Possibilidades à Educação Química. Alexandria, v. 10, n.2, p. 279-304, 2017. 
SOUZA, Luciana Sedano; CARVALHO, Anna Maria Pessoa. Ensino de Ciências e Formação da autonomia moral. Enseñanza de las Ciencias, número extra, 2005.

ZOMPÊRO, Andreia Freitas; LABURÚ, Carlos Eduardo. Atividades Investigativas no Ensino de Ciências: Aspectos históricos e diferentes abordagens. Ensaio, v. 13, n. 3, p. 67-80, 2011.

ZULIANI, Silvia Regina Quijadas Aro. Prática de ensino de Química e metodologia investigativa: uma leitura fenomenológica a partir da semiótica social. Tese de doutorado - São Carlos: UFSCar, 2006. 